\title{
Bazalt ve Atık Cam Agregalı Betonlarda Alkali-Silis Reaksiyonu Genleşmeleri ve Alkali Sızıntısı Seviyeleri
}

\author{
Cihat YÜKSEL ${ }^{1}$ \\ Ali MARDANI-AGHABAGLOU ${ }^{2}$ \\ Ahsanollah BEGLARIGALE ${ }^{3}$ \\ Halit YAZICI ${ }^{4}$ \\ Kambiz RAMYAR ${ }^{5}$ \\ Özge ANDICC ÇAKIR ${ }^{6}$
}

\begin{abstract}
öz
Agregada bulunan amorf silis ve boşluk çözeltisindeki alkaliler arasında gerçekleşen alkalisilis reaksiyonu (ASR), hasarla sonuçlanan önemli durabilite sorunlarındandır. $\mathrm{Bu}$ çalışmada, çeşitli karışımların alkali-silis reaktiviteleri, RILEM komitesi tarafından geliştirilen AAR-3 ve AAR-4 deneyleriyle araştırılmış̧ır. Bu hızlandırılmış deneylerde numunelerde yer alan alkalilerin ne kadarının dışarıya sızdığını belirlemek için kapların alt kısmında yer alan sudan örnekler alınmış ve atomik absorpsiyon spektrometrisi ile sodyum ve potasyum iyonlarının konsantrasyonu belirlenmiş̧tir. Sonuçlara göre alkalilerin önemli bir miktarının betonlardan dışarıya sızabildiği ve buna rağmen, özellikle atık cam agregası içeren karışımlarda halen çok yüksek miktarda genleşme ile karşılaşıldığı görülmüştür.
\end{abstract}

Anahtar Kelimeler: Alkali silis reaksiyonu, alkali sızıntısı, bazalt, atık cam.

\begin{abstract}
Alkali-Silica Reaction Expansions and the Extent of Alkali Leaching in Concretes Containing Basalt and Waste Glass as Aggregate

Alkali-silica reaction (ASR) which takes place between amorphous silica in the aggregate and alkalis in the pore fluid is one of the durability problems causing deterioration of mortars. In this study, alkali-silica reactivity of various mixtures was evaluated according to AAR-3 and AAR-4 tests developed by RILEM. For determining the extent of alkali leaching from the specimens during these accelerated tests, samples were taken from the
\end{abstract}

Not: Bu yazı

- $\quad$ Yayın Kurulu'na 04.05.2015 günü ulaşmıştır.

- 30 Haziran 2017 gününe kadar tartışmaya açıktır.

1 Ege Üniversitesi, İnşaat Mühendisliği Bölümü, İzmir - cihat.yuksel@ege.edu.tr 2 Uludağ Üniversitesi, İnşaat Mühendisliği Bölümü, Bursa - ali.mardani16@gmail.com

3 Dokuz Eylül Üniversitesi, İnşaat Mühendisliği Bölümü, İzmir - ahsan.beglari@gmail.com

4 Dokuz Eylül Üniversitesi, İnşaat Mühendisliği Bölümü, İzmir - halit.yazici@deu.edu.tr

5 Ege Üniversitesi, İnşaat Mühendisliği Bölümü, İzmir - kambiz.ramyar@ege.edu.tr

6 Ege Üniversitesi, İnşaat Mühendisliği Bölümü, İzmir - ozge.andic@ege.edu.tr 
Bazalt ve Attk Cam Agregalı Betonlarda Alkali-Silis Reaksiyonu Genleşmeleri ve ...

water accumulations at the bottom of the containers and sodium and potassium concentrations were determined using atomic absorption spectrometry. Results show that although a significant amount of alkalis can leach out, particularly waste glass aggregate leads to considerably high expansion levels.

Keywords: Alkali silica reaction, alkali leaching, basalt, waste glass.

\section{GíRiş}

Alkali-silis reaksiyonu (ASR), beton boşluk çözeltisindeki yüksek alkali konsantrasyonu ve agregada yer alan opal, kalsedoni, çört, volkanik cam, kripto- ve mikro-kristalin kuvars, deforme kuvars, tridimit, kristobalit, vb. gibi bazı silisli mineraller nedeniyle meydana gelmektedir. Higroskopik yapıdaki alkali-silis jelinin oluşumu ile çok fazla miktarda su emilmesi ve şişme olayı, betonun çekme dayanımı aşıldığında hasara yol açmaktadır [1-3].

Stanton'un reaksiyon kimyası, deney yöntemleri ve reaksiyonu önleme yollarından bahsettiği 1940 y1lındaki öncü çalışmasından [4] itibaren çok çeşitli deney yöntemleri ile kapsamlı araştırmalar gerçekleştirilmiş̧ir [5,6]. İlk olarak Oberholster ve Davies [7] tarafından önerilen hızlandırılmış harç çubuğu deneyi (HHÇD), sadece 16 günde çok hızlı sonuç vermesine rağmen, numunelerin maruz kaldığı koşullar çok şiddetli olduğundan $\left(80^{\circ} \mathrm{C}\right.$ ve $1 \mathrm{~N} \mathrm{NaOH}$ çözeltisine daldırma), ölçülen genleşmelerin normalde karşılaşılabilecek seviyelerin çok üzerinde kaldığı görüşü baskındır. Günümüze dek elde edilen tecrübe, HHÇD'nin tek başına güvenilir bir deney olmadığını ve bir agrega kaynağının bu deney uyarınca reaktif olarak nitelendirildiğinde ilave olarak beton prizma deneyinin (BPD) de gerçekleştirilmesi gerektiğini işaret etmektedir [6-9]. Sadece agregayı test eden yöntemlere kıyasla beton karışımın teste tabi tutulması daha güvenilir olup numunelerin $38^{\circ} \mathrm{C}$ 'de, kapalı kapların içinde ve su üzerinde saklanmasını öngören BPD sahada oluşabilecek genleşmeleri en iyi yansıtan yöntem olarak düşünülmektedir. Fakat BPD, agreganın reaktivitesini ölçmek için uygulandığında bir yıl ve mineral katkıların genleşmeyi önlemedeki etkinliğini ölçmek için uygulandığında iki yıl sürmektedir [10]. Hızlandırılmış beton prizma deneyi (HBPD) Ranc ve Debray tarafından 2002'de [11] geliştirilmiş olup sıcaklık seviyesi $38^{\circ} \mathrm{C}^{\prime}$ den $60^{\circ} \mathrm{C}$ 'ye çıkartılarak gerçek saha karışımlarının performansı incelenmiştir. Araştırmacılar BPD ve HBPD genleşmeleri arasında güçlü korelasyonlar elde etmiş ve $60^{\circ} \mathrm{C}^{\prime}$ lik yöntem için 56 günde $\% 0,02$ seviyesinde genleşme limiti önermiştir [12,13]. İlerleyen y1llarda farklı araştırmacılar tarafindan yürütülen çalışmalar, henüz standart bir yöntem olmayan HBPD için çok çeşitli deney sürelerinin ve genleşme limitlerinin önerilmesini beraberinde getirmiştir $[9,14,15]$.

2010'da sonuçları yayımlanan EU "PARTNER" Projesi'nde 10 farklı Avrupa ülkesinde bulunan 22 agrega kaynağ 1 RILEM tarafından geliştirilen test yöntemlerine tabi tutulmuştur. Çoğunlukla, hem RILEM AAR-3 (beton prizma deneyi, $38^{\circ} \mathrm{C}$ sıcaklıkta) hem de RILEM AAR-4 (beton prizma deneyi, $60^{\circ} \mathrm{C}$ sicaklıkta) yöntemleri, sahadaki performansı uzun yıllardır bilinen agregaların reaktivite düzeyini doğru olarak ortaya koyabilmiştir. Özellikle AAR-4 daha tutarlı sonuçlar üretebilmiş ve yavaş reaksiyona girme eğilimi bulunan agrega kombinasyonlarının reaktivitesini ortaya çıkarmada daha başarıı olmuştur [16]. Bazı araştırmacılara göre [11, 17-19] her iki yüksek sıcaklıklı beton prizma deneyinde de en önemli sıkıntılardan biri, beton prizmalarda başlangıçta yer alan alkalilerin önemli bölümünün testler sırasında dışarıya sızması ve böylelikle genleşme seviyesinin 
gerçeğin altında tahmin edilmesidir. Alkali sızıntısının hızı ve miktarı, deneylerde elde edilen genleşme-zaman ilişkisini belirleyen en önemli faktörlerden biri konumundadır.

Muhtemel ASR hasarını önceden belirleyebilmek için geçmişten günümüze sıklıkla tercih edilen mevcut standart deney metotları agreganın reaktivite potansiyelini belirlemeye yöneliktir. Bu çalışmanın ana amacı ise;

- reaktif nitelikte iki farklı agrega kullanılması neticesinde oluşan genleşme seviyelerinin RILEM tarafından henüz geliştirilen hızlandırılmış ve gerçekçi performans beton deneyleriyle ortaya koyulması ve

- deneyler esnasında karışımın alkali seviyesinde isteyerek ( $\mathrm{NaOH}$ ilavesi veya çimento alkalinitesindeki değişimle) ya da elde olmadan (beton bünyesindeki alkalilerin dışarıya göçüyle) oluşan değişimin genleşmelere etkisini incelemektir.

Makalede bazalt ve atık camların neden olduğu potansiyel reaktiviteyi belirleyebilmek için uygulanan AAR-3 ve AAR-4 deneyleri sonunda elde edilen veriler sunulmuştur. $\mathrm{NaOH}$ ilavesi, çimento alkali seviyesi ve atık cam agregası içeren karışımlarda $63 \mu$ m'dan küçük cam tanelerini uzaklaştırmanın genleşme değerleri üzerindeki etkileri de araştırılmıştır. Son olarak, beton prizmalardan alkali sızıntısı miktarını belirleyebilmek için atomik absorpsiyon spektrometrisi ile betonların altında yer alan sudaki sodyum ve potasyum iyonlarının konsantrasyonları da belirlenmiştir.

\section{DENEYSEL ÇALIŞMA}

\subsection{Kullanılan Malzeme}

\subsection{1. Çimento}

Beton karışımların hazırlanmasında Tablo 1'de özellikleri sunulmuş olan bir tip yüksek alkalili (HA - \%1.04 $\mathrm{Na}_{2} \mathrm{O}$ eşdeğeri) ve bir tip düşük alkalili (LA - \%0,63 $\mathrm{Na}_{2} \mathrm{O}$ eşdeğeri) olmak üzere iki farklı katkısız portland çimentosu kullanılmıştır.

Tablo 1. Çalışmada kullanılan çimentolar üzerinde gerçekleştirilen analiz sonuçları

\begin{tabular}{lccc}
\hline Bileşen veya özellik & $\begin{array}{c}\mathrm{HA} \\
\text { çimentosu }\end{array}$ & $\begin{array}{c}\text { LA } \\
\text { çimentosu }\end{array}$ & $\begin{array}{c}\text { Uygulanan deney } \\
\text { standard1/metodu }\end{array}$ \\
\hline Kızdırma kaybı (\%) & 2,09 & 1,53 & TS EN 196-2 \\
$\mathrm{SiO}_{2}(\%)$ & 19,72 & 19,54 & XRF/ ICP OES \\
$\mathrm{Al}_{2} \mathrm{O}_{3}(\%)$ & 5,31 & 4,80 & XRF/ ICP OES \\
$\mathrm{Fe}_{2} \mathrm{O}_{3}(\%)$ & 3,37 & 5,71 & XRF/ ICP OES \\
$\mathrm{CaO}(\%)$ & 62,33 & 62,65 & XRF/ ICP OES \\
$\mathrm{MgO}(\%)$ & 2,33 & 1,89 & XRF/ ICP OES \\
$\mathrm{SO}_{3}(\%)$ & 3,33 & 3,12 & TS EN 196-2 \\
$\mathrm{Na}_{2} \mathrm{O}(\%)$ & 0,53 & 0,37 & XRF/ ICP OES
\end{tabular}


Bazalt ve Atık Cam Agregalı Betonlarda Alkali-Silis Reaksiyonu Genleşmeleri ve ...

Tablo 1. Çalışmada kullanılan çimentolar üzerinde gerçekleştirilen analiz sonuçları (devam)

\begin{tabular}{lccc}
\hline Bileşen veya özellik & $\begin{array}{c}\text { HA } \\
\text { çimentosu }\end{array}$ & $\begin{array}{c}\text { LA } \\
\text { çimentosu }\end{array}$ & $\begin{array}{c}\text { Uygulanan deney } \\
\text { standard1/metodu }\end{array}$ \\
\hline Kızdırma kaybı (\%) & 2,09 & 1,53 & TS EN 196-2 \\
$\mathrm{K}_{2} \mathrm{O}(\%)$ & 0,77 & 0,40 & XRF/ ICP OES \\
$\mathrm{Cl}^{-}(\%)$ & 0,0136 & 0,0087 & XRF \\
\hline $\mathrm{Na}_{2} \mathrm{O}$ eşdeğeri $(\%)^{\mathrm{a}}$ & 1,04 & 0,63 & - \\
Çözünemeyen kalıntı (\%) & 0,48 & 0,20 & TS EN 196-2 \\
Yoğunluk $\left(\mathrm{g} / \mathrm{cm}^{3}\right)$ & 3,08 & 3,13 & Dijital piknometre ile \\
Özgül yüzey $-\mathrm{Blaine}\left(\mathrm{cm}^{2} / \mathrm{g}\right)$ & 3960 & 3570 & Otomatik Blaine cihazı ile \\
\hline${ }^{a} \mathrm{Na}_{2} \mathrm{O}$ eşdeğeri $=\mathrm{Na}_{2} \mathrm{O}+0.656 \mathrm{~K}_{2} \mathrm{O}$ & &
\end{tabular}

HA ve LA çimentoları sırasıyla Afyon ve Bolu çimento fabrikalarından temin edilmiştir. Bazı karışımlarda bu iki çimento tek başlarına, bazılarında ise \%50-50 oranlarında karıştırılarak ve böylelikle \%0,84 düzeyinde bir ilave $\mathrm{Na}_{2} \mathrm{O}$ eşdeğer içeriği elde edilerek kullanılmıştır.

\subsubsection{Agrega}

Kontrol karışımı niteliğindeki betonlarda agrega fazının tamamını üç farklı boy sınıfındaki (0/4 mm, 4/16 mm ve 11,2/22,4 mm) reaktif andezitik bazalt oluşturmuştur. Agreganın kaynağı İzmir'in kuzeyinde yer alan Aliağa yöresidir. Önceki tecrübelerden bazaltın camsı matrisinde yüksek $\mathrm{SiO}_{2}$ içeriğinin $(\sim 70 \%)$ reaktifliğe neden olduğu bilinmektedir [20].

Çalışmada kullanılan ikinci tip agrega ise soda-kireç camları kategorisine giren renksiz pencere camlarından elde edilen atıklardır. Toplanan atık cam kırıkları önce yıkanmış, daha sonra kurutulmuş ve darbe ve makaslama etkisi uygulayan bir çekiçli kırıcı yardımıyla ince agrega boyutuna getirilmiştir. Atık cam içeren karışımlarda cam agregası, sadece $0 / 3 \mathrm{~mm}$ veya $0,063 / 3 \mathrm{~mm}$ tane boyutlarında kullanılırken bu karışımlarda iri agrega olarak yine bazalt tercih edilmiştir. 0,063/3 mm tane sınıfı, kırıcıdan elde edilen cam agregasının 0,063 mm'lik elekten sslak elenmesiyle temin edilmiştir. Kırıcıdan elde edilen cam agregasının 1slak eleme neticesinde \%8'inin $0,063 \mathrm{~mm}$ 'lik elekten geçebildiği görülmüştür. Önceki çalışmalarımızdan [21] bilinen önemli bir diğer husus, soda-kireç camlarının ana bileşenlerinin yüksek miktarda $\mathrm{SiO}_{2}(\% 71,38)$ ve $\mathrm{Na}_{2} \mathrm{O}(\% 14,29)$ olduğudur.

Deneysel çalışma kapsamında kullanılan her bir boy sınıfındaki agreganın tane boyu dağılımları Şekil 1'de, beton karışımlarda bulunan agrega bileşimlerinin granülometrisi Tablo 2'de ve agregaların kimyasal kompozisyonları Tablo 3'te gösterilmektedir. Beton karışımlardaki agrega bileşimleri oluşturulurken deneyler için hazırlanan standart metinlerde [22] yer alan ince agreganın ve iri agreganın ağırlıkça oranlarının sırasıyla \%40 ve $\% 60$ olması önerisine uyulmuştur. 


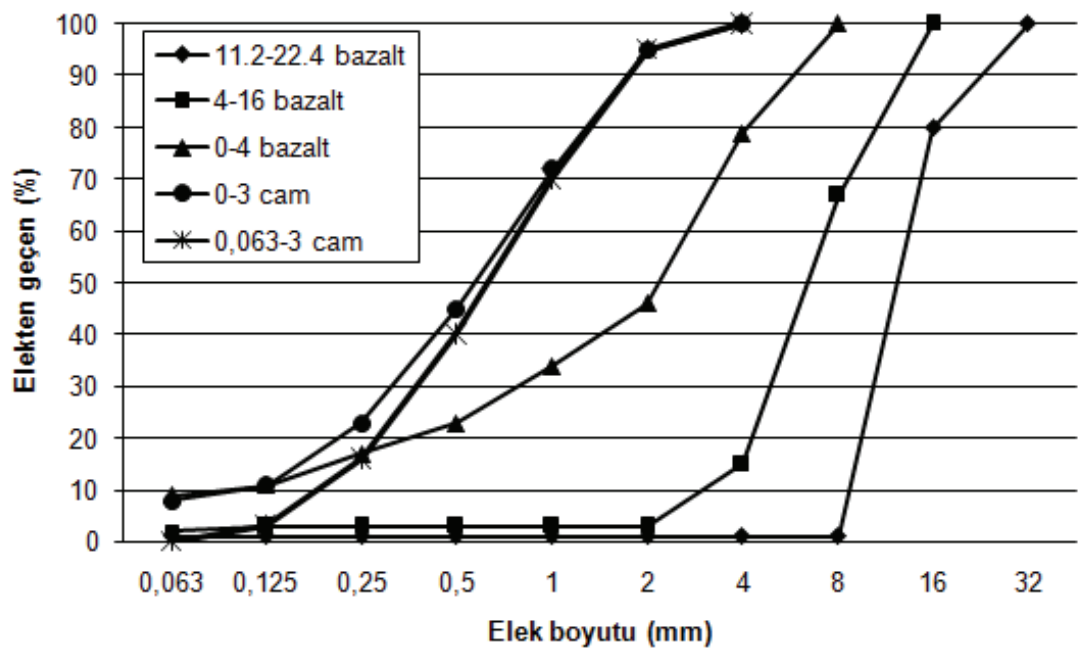

Şekil 1. Bazalt ve cam agregalarının gradasyon eğrileri

Tablo 2. Betonda yer alan ince agrega türüne göre agrega karışımları için hesaplanan gradasyon değerleri

\begin{tabular}{cccc}
\hline & \multicolumn{3}{c}{ Geçen $(\%)$} \\
\cline { 2 - 4 } Elek Açıklığı $(\mathrm{mm})$ & \multicolumn{3}{c}{ Karışımdaki ince agrega türü } \\
\cline { 2 - 4 } & $0 / 4$ bazalt & $0 / 3$ cam & $0,063 / 3$ cam \\
\hline 31,5 & 100 & 100 & 100 \\
16 & 94 & 94 & 94 \\
8 & 60 & 60 & 60 \\
4 & 36 & 45 & 45 \\
2 & 20 & 39 & 39 \\
1 & 15 & 30 & 29 \\
0,5 & 10 & 19 & 17 \\
0,25 & 8 & 10 & 8 \\
0,125 & 6 & 6 & 2 \\
0,063 & 5 & 4 & 0 \\
\hline
\end{tabular}


Bazalt ve Atık Cam Agregalı Betonlarda Alkali-Silis Reaksiyonu Genleşmeleri ve ...

Tablo 3. Bazalt ve cam agregalarının kimyasal kompozisyonları

\begin{tabular}{lcc}
\hline Bileşen, \% & Bazalt & Atık cam \\
\hline $\mathrm{SiO}_{2}$ & 54,08 & 71,38 \\
$\mathrm{Al}_{2} \mathrm{O}_{3}$ & 14,37 & 1,30 \\
$\mathrm{Fe}_{2} \mathrm{O}_{3}$ & 6,68 & 0,107 \\
$\mathrm{CaO}$ & 8,71 & 8,28 \\
$\mathrm{MgO}$ & 2,50 & 4,27 \\
$\mathrm{Na} 2 \mathrm{O}$ & 2,41 & 14,29 \\
$\mathrm{~K}_{2} \mathrm{O}$ & 1,67 & 0,07 \\
$\mathrm{TiO}_{2}$ & - & 0,076 \\
$\mathrm{Cl}^{-}$ & - & - \\
$\mathrm{SO}_{3}$ & - & 0,23 \\
$\mathrm{~K}_{3}$ dirma kaybi & 6,84 & - \\
$\mathrm{Belirlenemeyen}$ & 2,74 & - \\
\hline
\end{tabular}

\subsection{Deney Yöntemleri (RILEM AAR-3 ve AAR-4)}

Her bir karışımdan altı adet $75 \times 75 \times 285 \mathrm{~mm}$ boyutlarında prizmalar hazırlanmış ve üçü AAR-3, diğer üçü de AAR-4 deneyine maruz bırakılmıştır. Numuneler ilk 24 saat boyunca kalıplarda $20 \pm 2^{\circ} \mathrm{C}$ sicaklık ve $\% 90$ bağıl neme sahip bir odada saklanmış ve sonrasında kalıplar sökülmüştür. Daha sonra $20 \pm 2^{\circ} \mathrm{C}$ sıcaklığa sahip odada numuneler tartılmış $\left(\mathrm{W}_{0}\right)$ ve ilk komparatör okuması $\left(1_{0}\right)$ gerçekleştirilmiştir. Bir karışıma ait üç numuneyi içerisinde dik olarak muhafaza edebilecek boyutlarda standart kaplar kullanılmıştır. Kapların alt kısmına 20-30 mm yüksekliğe kadar saf su yerleştirilmiş ve numunelerin birbirlerine, kapların kenarlarına ve aşağıda bulunan suya değmemesine özen gösterilmiştir. AAR-3 deneyinde numuneleri içerisinde barındıran kaplar, $38^{\circ} \mathrm{C}^{\prime} l i k$ sıcaklığı sağlayan bir odaya (Şekil 2a), AAR-4'te ise $60^{\circ} C^{\prime}$ lik sıcaklığı sağlayan bir kabine (Şekil 2b) yerleştirilmiştir.

Her iki beton prizma deneyinde de ilerleyen haftalarda herhangi bir yaştaki boy $\left(l_{i}\right)$ ve ağırlık $\left(\mathrm{W}_{\mathrm{i}}\right)$ ölçümünden 24 saat önce numunelerin kapların içerisinde kalması koşuluyla $20 \pm 2{ }^{\circ} \mathrm{C}$ 'ye kadar soğumasına izin verilmiş ve tüm ölçümler $20 \pm 2^{\circ} \mathrm{C}$ sıcaklığa sahip oda içerisinde alınmıştır. Yakın zamanda gerçekleştirilen bir çalışmada [23], bazı beton prizma deneylerinde başvurulan bir yöntem olan numunelerin 1slak kumaşlara sarılması işleminin, özellikle erken yaşlarda betondan dışarıya alkali sızıntısını hızlandırabildiği fark edilmiştir. Dolayısıyla deneysel çalışmada bu tip bir sargılama uygulanmamıştır.

Numunelerden dışarıya sızan alkali miktarını bulabilmek için kapların alt kısmında yer alan sudan $\sim 10$ ml'lik örnekler alınmıştır. Bu arada alınan örnek yerine kaplara aynı miktarda saf su ilave edilmiştir. Düzenli aralıklarla gerçekleştirilen genleşme ölçümlerinin hemen sonrasında atomik absorpsiyon spektrometrisi yöntemiyle suda yer alan sodyum ve potasyum iyonu konsantrasyonları $\mathrm{mg} / \mathrm{l}$ cinsinden belirlenmiştir. Çalışmanın bu aşaması Ege Üniversitesi Kimya Mühendisliği Bölümü laboratuvarlarında Varian-SpectrAA 10 plus tipinde bir spektrometre kullanılarak gerçekleştirilmiştir (Şekil 3a). Bu yöntemde oyuk 
katot lambaları (Şekil 3b) kullanılmakta olup temel prensip, miktarı belirlenmek istenilen elementin sadece kendine özgü dalga boyuna sahip ışımayı absorplayacağıdır. Bu nedenle katot, miktarı belirlenmek istenilen elementten yapılmış̧ır. Işık kaynağının içinde anot uç tarafindan iyonize edilen soy gazlar hapsedilmiştir [24].

Bir kapalı kap içerisinde herhangi bir karışıma ait üç adet numune yer aldığından kaptan alınan su örneğinde ölçülen alkali sızıntısı miktarı üçe bölünmüștür. Bir başka ifadeyle kaplarda yer alan bir karışıma ait üç adet numuneden de eşit miktarda sızıntı gerçekleştiği varsayımı kabul edilmiştir [19].

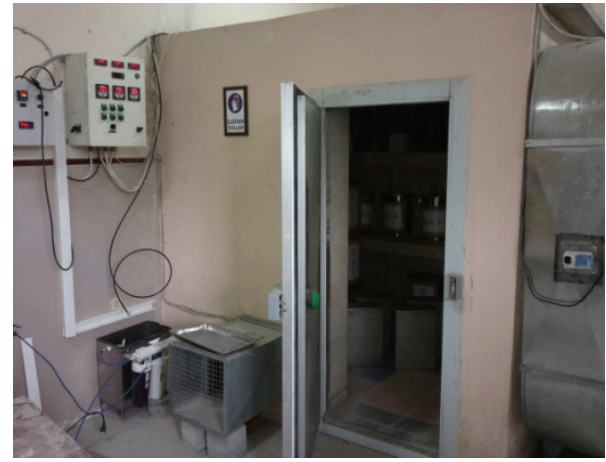

(a)

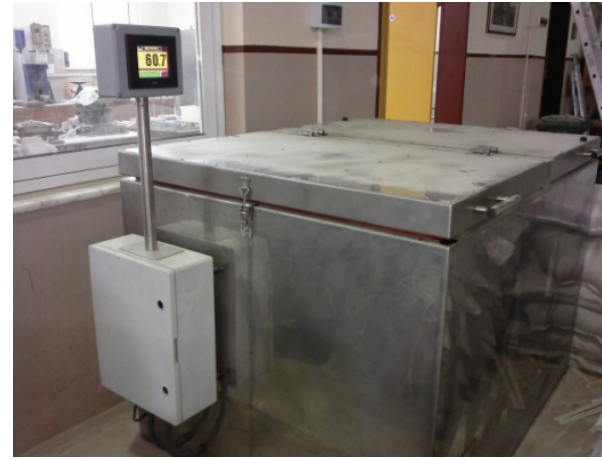

(b)

Şekil 2. a) AAR-3 deneyi için $38^{\circ} \mathrm{C}^{\prime} l i k$ sicaklı̆̆ın sağlandiğı oda, b) AAR-4 deneyi için $60^{\circ} C^{\prime}$ 'ik sicaklığın sağlandı̆̆g kabin

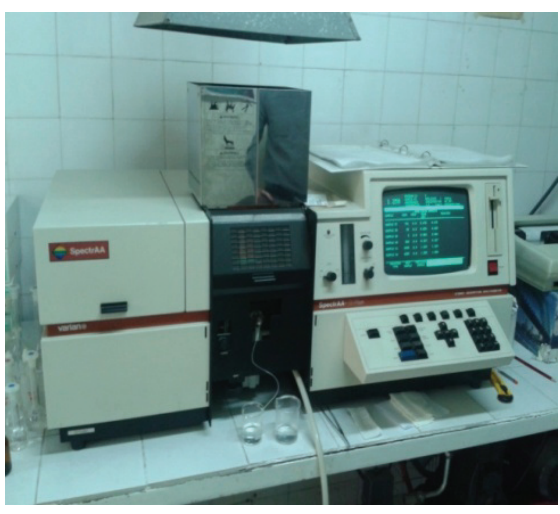

(a)

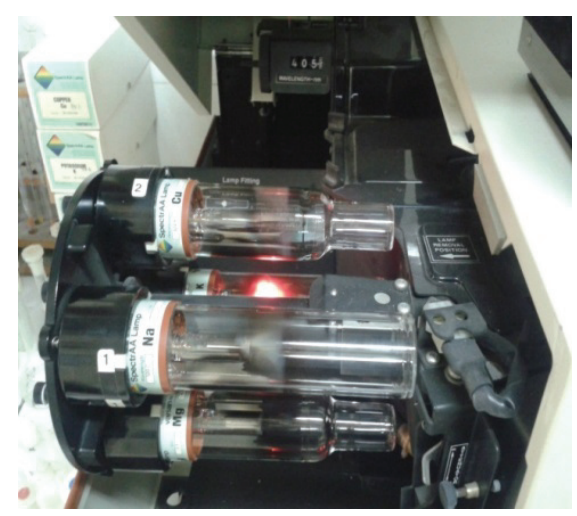

(b)

Şekil 3. Atomik absorpsiyon spektrometrisinde kullanılan a) deney cihazının ve b) içerisindeki oyuk katot lambalarının görünümü 
Bazalt ve Attk Cam Agregalı Betonlarda Alkali-Silis Reaksiyonu Genleşmeleri ve ...

\subsection{Karışım Oranları}

Deneysel çalışma kapsamında dokuz adet karışım AAR-3 ve AAR-4 yöntemleri uyarınca deneylere tabi tutulmuştur. Tablo 4 'te karışım oranları sunulmuş olan ve su/çimento oranı 0,5 olan ilk üç seri, agrega olarak sadece bazalt ve bağlayıcı olarak da sadece LA çimentosu içermekte olup üçü de kontrol karışımları olarak adlandırılmıştır. Uygulanan AAR-3 ve AAR-4 deneylerinde gerektiğinde karışım suyuna $\mathrm{NaOH}$ ekleyerek beton karışımların alkali içeriğini bağlayıcı ağırlı̆̆ının \%1,25'ine yükseltme gerekliliği bulunmaktadır. Karışımlardaki çimento içeriği $440 \mathrm{~kg} / \mathrm{m}^{3}$ olduğundan standartlara uygun hazırlanan karışımın alkali içeriğinin $\mathrm{Na}_{2} \mathrm{O}$ eşdeğeri cinsinden $5,50 \mathrm{~kg} / \mathrm{m}^{3}$ e eşit olması gerekmektedir. Alkali seviyesinin de genleşmeler üzerindeki etkisini anlayabilmek için $5,50 \mathrm{~kg} / \mathrm{m}^{3}$ alkali seviyesine sahip kontrol kodlu karışımın yanı sıra 4,40 ve $6,60 \mathrm{~kg} / \mathrm{m}^{3}$ alkali yüklerine sahip kontrol- ve kontrol+ kodlu karışımlar da hazırlanmıştır.

Tablo 4. Kontrol karış̧ımlarında malzeme oranları $\left(\mathrm{kg} / \mathrm{m}^{3}\right)$

\begin{tabular}{lccc}
\hline & Kontrol- & Kontrol & Kontrol+ \\
\hline Düşük alkalili (LA) çimento & 440 & 440 & 440 \\
$\mathrm{Su}$ & 220 & 220 & 220 \\
$0 / 4$ bazalt & 698 & 696 & 696 \\
$4 / 16$ bazalt & 523 & 522 & 522 \\
$11,2 / 22,4$ bazalt & 523 & 522 & 522 \\
Eklenen $\mathrm{NaOH}$ & 2,12 & 3,57 & 5,02 \\
Süperakışkanlaştırıcı & 4,5 & 4,9 & 5,1 \\
\hline Toplam & 2406 & 2404 & 2405 \\
\hline Alkali içeriği (kg/m $\left.{ }^{3}\right)$ & 4,40 & 5,50 & 6,60 \\
\hline Alkali içeriği (bağlayıcının \%'si) & 1,00 & 1,25 & 1,50 \\
\hline
\end{tabular}

Tablo 5. Cam agregası içeren karışımlarda malzeme oranları $\left(\mathrm{kg} / \mathrm{m}^{3}\right)$

\begin{tabular}{lcccccc}
\hline & $0 / 3 \mathrm{HA}$ & $0 / 3 \mathrm{LA}$ & $0 / 3 \mathrm{MA}$ & $0,063 / 3 \mathrm{HA}$ & $0,063 / 3 \mathrm{LA}$ & $0,063 / 3 \mathrm{MA}$ \\
\hline Düşük alkalili (LA) çimento & 0 & 440 & 220 & 0 & 440 & 220 \\
Yüksek alkalili (HA) çimento & 440 & 0 & 220 & 440 & 0 & 220 \\
$\mathrm{Su}$ & 220 & 220 & 220 & 220 & 220 & 220 \\
$4 / 16$ bazalt & 501 & 499 & 500 & 501 & 499 & 500 \\
$11.2 / 22.4$ bazalt & 501 & 499 & 500 & 501 & 499 & 500 \\
0/3 cam & 667 & 665 & 666 & 0 & 0 & 0 \\
0/3 cam (63 $\mu$ m'dan elenmiş) & 0 & 0 & 0 & 667 & 665 & 666 \\
Süperakışkanlaştırıcı & 1,0 & 1,4 & 1,1 & 0,6 & 0,8 & 0,6 \\
Toplam & 2329 & 2323 & 2326 & 2329 & 2323 & 2326 \\
\hline Alkali içeriği $\left(\mathrm{kg} / \mathrm{m}^{3}\right)$ & 4,60 & 2,79 & 3,69 & 4,60 & 2,79 & 3,69 \\
\hline Alkali içeriği (bağlayıcının & 1,04 & 0,63 & 0,84 & 1,04 & 0,63 & 0,84 \\
\%'si) & & & & & & \\
\hline
\end{tabular}


Hazırlanan diğer altı karışımda ise ince agrega boyutundaki atık cam agregası yer almaktadır. Tablo 5'te görüldüğü üzere bu karışımlar LA ve/veya HA çimentosu içermekte olup toplam çimento içeriği her birinde yine $440 \mathrm{~kg} / \mathrm{m}^{3}$ 'e ve su/çimento oranı $0,5^{\prime} \mathrm{e}$ eşittir. Cam agregası içeren bu karışımlarda $\mathrm{NaOH}$ ilavesi uygulanmamış olup karışım kodlarında yer alan LA, HA ve MA kısaltmaları sırasıyla düşük alkalili, yüksek alkalili veya orta seviyede alkalili çimento kullanıldığını ifade etmektedir. Yine kodlarda yer alan sayılar ise camın karışımda kullanıldığı tane boyutu aralığını simgelemektedir.

Tablo 4 ve Tablo 5'ten görüldüğü üzere çalışma kapsamında hazırlanan tüm karışımlarda gerektiğinde üreticinin önerdiği dozaj aralığında polikarboksilik eter esaslı yüksek oranda su azaltıcı beton katkısı kullanılarak taze betonda çökme değerinin $10 \pm 1 \mathrm{~cm}$ aralığında kalması sağlanmıştır.

Hazırlanan karışımların tamamında Tablo 4 ve Tablo 5 'te belirtilen alkali içerikleri hesaplanırken boşluk suyu çözeltisine sadece kullanılan çimento kaynaklı alkali salındığı varsayılmıştır.

\section{DENEY SONUÇLARI VE TARTIŞMA}

Şekil 4 ve Tablo 6 'da $38^{\circ} \mathrm{C}$ sicaklığa, Şekil 5 ve Tablo $7^{\prime}$ 'de ise $60^{\circ} \mathrm{C}$ sicaklığa maruz bırakılan karışımların zamana bağlı genleşmeleri verilmiş̧ir. Sonuçlara göre bazalt içeren karışımların genleşmeleri, atık camlı karışımlara kıyasla çok düşük kalmıştır. Grafiklerdeki kontrol ve kontrol+ karışımlarının genleşme-zaman ilişkisi kesikli çizgilerle işaretlenerek verilerin daha rahat anlaşılması için Şekil $4 \mathrm{c}$ ve $5 \mathrm{c}^{\prime}$ de ayrı olarak da sunulmuştur.

AAR-3 ve AAR-4 deneylerinden elde edilen sonuçların değerlendirilmesinde kullanılacak olan genleşme limitleri RILEM komitesi tarafindan henüz kesin olarak belirlenmemiş olup bunun için öncelikle laboratuvar deneylerinden elde edilen genleşmelerle saha betonlarının uzun dönemli genleşmeleri arasında güçlü korelasyonlara ihtiyaç duyulduğu ifade edilmektedir. Yine de EU "PARTNER" Projesi'nde elde edilen ilk sonuçlar uyarınca AAR3 ve AAR-4 deneylerinde önerilen genleşme limitleri sırasıly 1 yıllık sürede $\% 0,05$ ve 20 haftalık sürede $\% 0,03$ şeklindedir [16]. Şekil 4'teki sonuçlara göre kontrol karışımlarının nihai genleşmeleri, belirtilen genleşme limitinin yarısına bile ulaşmamıştır. $60^{\circ} \mathrm{C}$ 'ye maruz kalma sonucu oluşan sonuçların yer aldığı Şekil 5'e göre de kontrol+ karışımının genleşmesi limiti zorlukla aşabilmiş, ama kontrol karışımı yine "reaktif olmayan" kategorisinde yer almıştır. Ayrıca kontrol- karışımının her iki sıcaklık seviyesinde de deney süreleri boyunca hiç genleşme göstermediği belirlenmiş̧tir. Bazalt agregasının ince fraksiyonunun ön deneylerimizde $80^{\circ} \mathrm{C}$ sicaklıktaki harç çubuğu deneyinde 14 günde $\% 0,5$ mertebesinde genleşme ürettiği bilinmesine rağmen (potansiyel reaktivite için harç çubuğu deneyinde limit $\% 0,1^{\prime}$ dir), beton prizma deneyi neticesinde oldukça düşük genleşme seviyeleri oluşmuştur. Bazalt agregasının farklı deney yöntemlerine tabi tutulduğunda bu şekilde farklı davranışlar sergilemesine dair açıklamalar literatürde mevcuttur. Reaktif camsı veya kripto-kristalin bileşenler, yoğunluğu yüksek bu tip iri agregalarda yoğun yapının içerisinde hapsolup alkalilerin saldırısından korunabilmekte ve böylelikle beton prizma deneyinde daha düşük genleşmeler oluşabilmektedir [13,25]. 


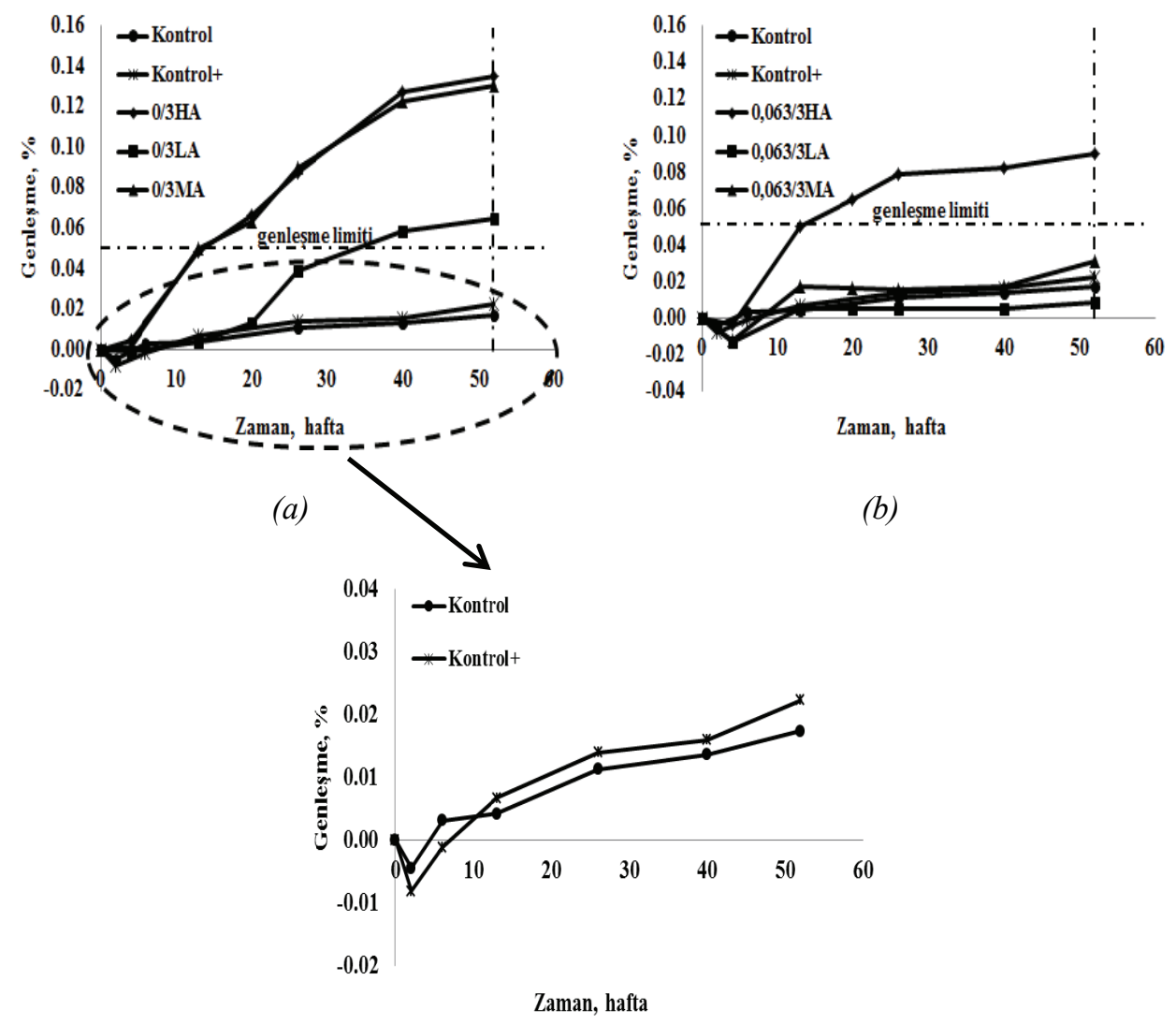

Şekil 4. Kontrol ve a) 0/3 mm, b) 0,063/3 mm cam agregası içeren karışımların $38^{\circ} \mathrm{C}$ 'ye maruz kalma sonrasındaki genleşme-zaman grafiği, (c) kontrol karışımlarına ait ilişkinin daha detaylı görüntüsü

Diğer taraftan cam agregası içeren karışımlarda oldukça yüksek genleşmelerle karşılaşılmıştır. Şekil 4a'ya göre sıcaklı̆ı̆ın $38^{\circ} \mathrm{C}$ olması durumunda düşük alkalili çimento içeren 0/3LA karışımının genleşme seviyeleri, diğer iki karışıma nazaran tüm yaşlarda oldukça düşük kalmıştır. Şekil 4a ve Şekil 4b kıyaslandığında cam agregasından $63 \mu$ m'dan küçük tanelerin uzaklaştırılmasının her üç camlı karışım için de daha küçük genleşme değerlerine yol açtığı söylenebilir. Şekil 4b'de genleşme-zaman eğrisinin $0,063 / 3 \mathrm{HA}$ karışımı için 26 haftadan, 0,063/3LA ve 0,063/3MA karışımları için 12 haftadan sonra yataylaşma eğiliminde olduğu görülmektedir. Fakat bu grafikte 40 . ve 52 . haftalar arasında ortaya çıkan genleşme davranışları, reaksiyonların henüz sonlanmamış olabileceğini işaret etmektedir. Deney süresi tamamlanmış olsa da 52. haftadan sonra alınacak ölçümler, davranışın daha iyi anlaşılmasını sağlayacaktır. 

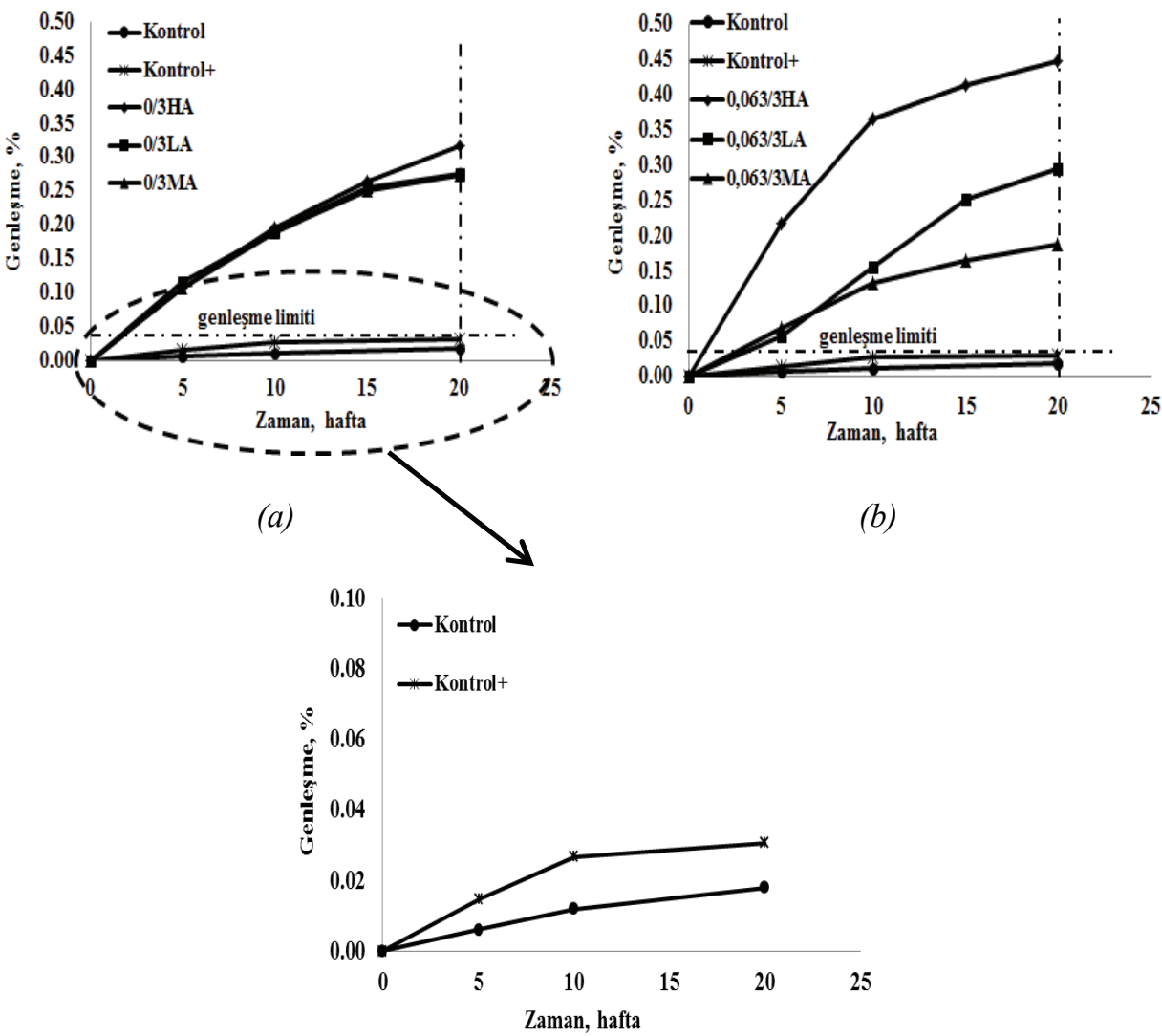

Şekil 5. Kontrol ve a) 0/3 mm, b) 0,063/3 mm cam agregast içeren karlşımların $60^{\circ} \mathrm{C}^{\prime} y e$ maruz kalma sonrasındaki genleşme-zaman grafiği, (c) kontrol karışımlarına ait ilişkinin daha detayll görüntüsü

Tablo 6. AAR-3 deneyleri boyunca karışımların gösterdiği genleşmeler (\%)

\begin{tabular}{lcccccccc}
\hline & \multicolumn{7}{c}{ Hafta } \\
\hline & 2 & 4 & 6 & 13 & 20 & 26 & 40 & 52 \\
\hline Kontrol & $-0,0045$ & - & 0,0031 & 0,0041 & - & 0,0112 & 0,0136 & 0,0173 \\
Kontrol+ & $-0,0081$ & - & $-0,0012$ & 0,0067 & - & 0,0139 & 0,0159 & 0,0223 \\
0/3LA & - & $-0,0006$ & - & 0,0040 & 0,0134 & 0,0390 & 0,0588 & 0,0648 \\
0/3HA & - & 0,0044 & - & 0,0485 & 0,0667 & 0,0876 & 0,1274 & 0,1348 \\
0/3MA & - & 0,0013 & - & 0,0503 & 0,0631 & 0,0900 & 0,1223 & 0,1308 \\
0,063/3LA & - & $-0,0133$ & - & 0,0048 & 0,0047 & 0,0048 & 0,0049 & 0,0087 \\
$0,063 / 3$ HA & - & $-0,0037$ & - & 0,0497 & 0,0647 & 0,0785 & 0,0825 & 0,0896 \\
$0,063 / 3$ MA & - & $-0,0120$ & - & 0,0168 & 0,0167 & 0,0151 & 0,0174 & 0,0312 \\
\hline
\end{tabular}


Bazalt ve Atık Cam Agregalı Betonlarda Alkali-Silis Reaksiyonu Genleşmeleri ve ...

Tablo 7. AAR-4 deneyleri boyunca karışımların gösterdiği genleşmeler (\%)

\begin{tabular}{lcccc}
\hline \multicolumn{5}{c}{ Hafta } \\
\hline Kontrol & 5 & 10 & 15 & 20 \\
Kontrol+ & 0,0062 & 0,0120 & - & 0,0181 \\
0/3LA & 0,0147 & 0,0267 & - & 0,0307 \\
0/3HA & 0,1168 & 0,1928 & 0,2555 & 0,2768 \\
0/3MA & 0,1083 & 0,1960 & 0,2662 & 0,3183 \\
0,063/3LA & 0,1067 & 0,1893 & 0,2520 & 0,2747 \\
0,063/3HA & 0,0573 & 0,1561 & 0,2517 & 0,2960 \\
$0,063 / 3 \mathrm{MA}$ & 0,2173 & 0,3667 & 0,4133 & 0,4480 \\
\hline
\end{tabular}

Şekil 5a’ya göre $60^{\circ} \mathrm{C}$ sıcaklıkta gerçekleştirilen deneylerde karışımdaki çimentonun alkalinitesinin değişimi, genleşme sonuçlarını önemli ölçüde etkilememiştir. Fakat Şekil 5b'ye göre yüksek alkalili çimento kullanımı, 10. haftada diğer iki karışımın genleşmesinin 2 katından fazla bir boy değişimine yol açmış, 20. haftada da diğer iki karışıma göre yine daha fazla genleşme oluşturmuştur. Literatürde yer alan bazı araştırmalar [26-28], camın yeterli inceliğe öğütülmesi durumunda puzolan niteliği kazanabildiğini ve hatta alkali-silis reaksiyonu nedeniyle oluşan genleşmeleri azaltıcı yönde rol oynayabildiğini açıklamaktadır. Şekil 5a'daki 0/3HA ve Şekil 5b'deki 0,063/3HA karışımlarının performansları karşılaştırıldığında, karışımda $63 \mu \mathrm{m}$ 'dan küçük cam parçalarının bulunmasının daha düşük genleşme seviyesine neden olduğu görülmektedir. Fakat yine $60^{\circ} \mathrm{C}$ sicaklıkta ve 20. haftada 0/3LA-0,063/3LA ve 0/3MA-0,063/MA karışımlarında elde edilen genleşmeler tam tersi bir eğilimin varlığını göstermekte ve dolayısıyla camın puzolanik etkisinden bahsedilmesini engellemektedir. Elde edilen sonuçlardan, cam tozunun puzolanik aktivitesi üzerinde boşluk çözeltisinin alkalinitesinin etkin rol oynadığ anlaşılmaktadır.

Camın 63 md dan küçük tanelerinin uzaklaştırılması durumunda genleşmeleri azaltıcı veya arttırıcı etkisinin varlığıyla ilgili genel bir kanıya ulaşılmasının zorluğu aşağıda sıralanan şu faktörlerin varlığından ve bunların zaman zaman birbirleriyle yarışmasından kaynaklanmaktadır:

- Deneylerde kullanılan ve soda-kireç camları kategorisine giren renksiz camlarda alkali miktarı \%14-15 mertebelerinde olmaktadır. Bu alkalilerin cam bünyesinden salınıp salınmadığının kontrolü gerekmekte olup bu deneyler ilk yazarın doktora tezi çalışmaları kapsamında başlatılmıştır. Yapılan bu deneylerde cam örnekler $\mathrm{NaOH}$ çözeltisinde bekletilip çözeltiye salınan $\mathrm{K}^{+}$iyonu ve $\mathrm{KOH}$ çözeltisinde bekletilip çözeltiye salınan $\mathrm{Na}^{+}$ iyonu ölçümleri gerçekleştirilmiştir. Bu işlemler de AAR-3 ve AAR-4 deneyleri gibi $38^{\circ} \mathrm{C}$ ve $60^{\circ} \mathrm{C}^{\prime}$ de gerçekleştirilmektedir. Ayrıca cam agregaları $<0,125 \mathrm{~mm}, 0,125-1 \mathrm{~mm}$ ve $1-4$ mm olmak üzere üç farklı boy sınıfında deneye tabi tutulmuştur. RILEM tarafından (AAR8) bu deneylerin, salınan alkali miktarı-zaman grafikleri yataylaşana kadar sürmesi önerilmektedir. Henüz her iki sıcaklık seviyesinde de alkali salınımının sona erdiğine dair bulguya rastlanmamıştır. Ayrıca $38^{\circ} \mathrm{C}$ 'de bekletilen örnekler için 1 yıl süre henüz 
dolmamıştır. $60^{\circ} \mathrm{C}$ 'de gerçekleştirildiği deneyde ise 20 haftalık sonuçlara (AAR-4 deneyinin sonuna denk gelmekte) göre daha küçük camlardan daha çok alkali salındığı görülmüştür. $60^{\circ} \mathrm{C}$ 'de sızan alkali miktarları, camların bünyesindeki alkalilerin $\% 1,2$ 2,6'sına denk gelmiştir. Bu miktarlar ilk olarak küçük değerler olarak anlaşılsa da karışımlarda yaklaşık $665 \mathrm{~kg} / \mathrm{m}^{3}$ cam kullanıldığ ve camın yaklaşık \%15 oranında alkali içeriğine sahip olduğu düşünüldüğünde, camlardan gelen alkali katkısı $\sim 2 \mathrm{~kg} / \mathrm{m}^{3}$ mertebelerindedir. $38^{\circ} \mathrm{C}$ 'deki ilk bulgularda ise salınan alkali miktarları daha düşük seviyelerdedir.

- Camın 63 mm'dan küçük tanelerinin uzaklaştırılması durumunda kuşkusuz beton örneklerin geçirimliliği de artmaktadır. Geçirimliliğin artması beton bünyesine suyun girişini kolaylaştırmakta, alkali-silis jelinin su emip şişmesiyle genleşmeleri arttırmaktadır. Ama geçirimlilikteki artış aynı zamanda beton bünyesindeki alkalilerin dışarıya sızmasını da kolaylaştırmakta ve bu durum da genleşmeleri azaltıcı yönde etki etmektedir. Özellikle $60^{\circ} \mathrm{C}$ gibi yüksek sıcaklık seviyelerinde gerçekleştirilen deneylerde betonun bünyesinden dışarıya alkali sızıntısının önemli rol oynadığı bilinmektedir. Yakın zamanda yapılan bir çalışmada [19] deney sonunda, başlangıçta yer alan alkalilerin sızma oranının yaklaşık \%40'lara vardığ 1 belirlenmiştir. (Tablo 8 'de deneysel çalışmada ölçülen değerler sunulmuştur.)

- Atık cam, silis miktarı yüksek, amorf yapıya sahip ve reaktif bir agregadır. Betonda kullanılan geleneksel agregalarda alkali-silis reaksiyonu genelde agrega-çimento hamuru ara yüzeyinde başlamakta, bu durum da yüzey alanı daha fazla olan ince agregaların genellikle daha çok reaktivite göstermesine neden olmaktadır. Fakat cam agregası için durum farklı gerçekleşmektedir. Camların beton karışımına eklenmeden önce halihazırda bünyesinde çoğunlukla kırılma esnasında oluşan mikro-çatlaklar bulunmaktadır. Camlarda alkali-silis reaksiyonu bu çatlakların içerisinde başlamaktadır [29]. Bu durum da camla yapılan çalışmalarda camın tane boyutunun artmasıyla bünyesindeki çatlak boyutu ve miktarı arttığından reaktivitesinin de artmasına neden olmuştur. Camın tane boyutu belli bir seviyeye kadar azaldıkça genleşme yaratmamakta hatta yeterli inceliğe öğütüldüğünde var olan genleşmeleri bile azaltmaktadır. Bu faktörler düşünüldüğünde $63 \mu$ m'dan küçük tanelerin genleşmeleri azaltması beklenebilir.

Deneyler süresince numunelerde incelenen genleşme davranışlarının yanı sıra ağırlıklarındaki değişimler de kaydedilmiştir. Beton prizma deneylerinde numunlerin aslında kontrol amaçlı olarak tartılması istenmekte, genleşmeler arttıkça ağırlık değerlerinde de artışlar oluşması beklenmektedir. $\mathrm{Bu}$ durum, reaksiyonlar neticesinde oluşan alkali-silis jelinin bünyesine su almasıyla ilgilidir. Yürütülen çalışmalar neticesinde elde edilen ağırlık artışı-zaman ilişkileri, genleşme-zaman eğilimlerine benzer çıkmıştır. Örnek teşkil etmesi açısından cam agregası içeren altı adet karışımda her yaştaki ölçümler dikkate alınarak genleşme (\%) - ağırlık artışı (\%) grafikleri elde edilmiştir. Şekil 6a'da $38^{\circ} \mathrm{C}$ 'de kürlenen örnekler için, Şekil $6 \mathrm{~b}$ 'de ise $60^{\circ} \mathrm{C}$ 'de kürlenen örnekler için çizilen grafikler görülmektedir. Buna göre numune genleşmeleri arttıkça ağırlık artışı değerleri parabolik olarak artış göstermekte olup her iki deneyde de elde edilen korelasyonlar iyi düzeydedir ve daha yüksek genleşme seviyelerinde genleşme hızı, ağıllık artış hızına kıyasla daha yüksektir.

Genleşme ve ağırlık ölçümlerine ilave olarak, numunelerin saklanmasında kullanılan kapların alt kısımlarında yer alan sudaki alkali iyonu $\left(\mathrm{Na}^{+}\right.$ve $\left.\mathrm{K}^{+}\right)$miktarları da 
Bazalt ve Atık Cam Agregalı Betonlarda Alkali-Silis Reaksiyonu Genleşmeleri ve ...

belirlenmiştir. Konsantrasyon değerleri spektrometre yardımıyla ppm cinsinden belirlendikten sonra atomik ağırlıkları göz önünde bulundurularak bu değerler $\mathrm{Na}_{2} \mathrm{O}$ ve $\mathrm{K}_{2} \mathrm{O}$ miktarlarının tespitinde kullanılmıştır. $\mathrm{Na}^{+}$iyon miktarı 2,696 ile çarpılarak $\mathrm{Na}_{2} \mathrm{O}$ içeriği elde edilirken $\left(\mathrm{Na}_{2} \mathrm{O}: 62, \mathrm{Na}: 23,62 / 23=2,696\right) \mathrm{K}^{+}$içeriği de 2,410 katsayısı ile çarpılmış ve $\mathrm{K}_{2} \mathrm{O}$ seviyesi elde edilmiştir $\left(\mathrm{K}_{2} \mathrm{O}: 94, \mathrm{~K}: 39,94 / 39=2,410\right)$. Daha sonra bu değerler eşdeğer $\mathrm{Na}_{2} \mathrm{O}$ içeriğine çevrilmiş ve yorumlar, başlangıçta yer alan alkalilerin ne kadarının suya sızdığı üzerine yapılmıştır. Dokuz karışım için her iki deney yönteminde deney süreleri sonunda belirlenen sızma miktarları Tablo 8'de sunulmuştur. Hesaplamalar yapılırken kabul edilen iki adet varsayım; alkalilerin sadece çimento kaynaklı olduğu ve kapların altı kısmında yer alan suyun hacminin deneyler süresince sabit kaldığıdır.

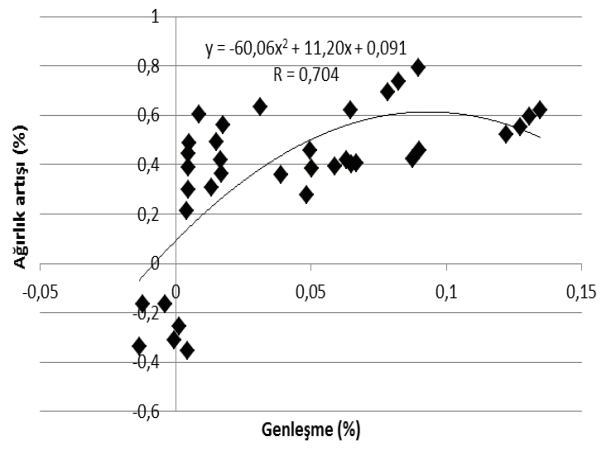

(a)

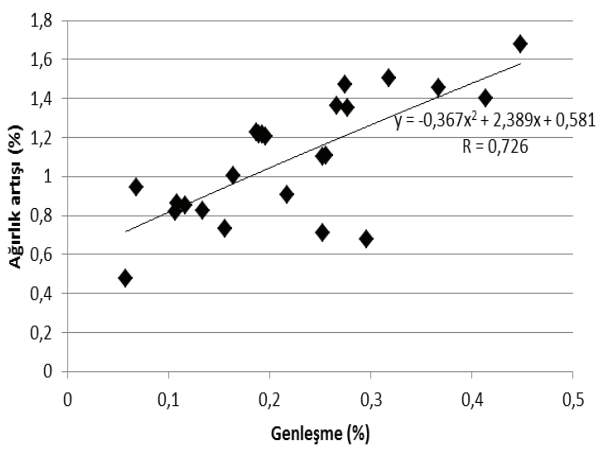

(b)

Şekil 6. Cam agregası içeren a) $38^{\circ} \mathrm{C}$ 'de b) $60^{\circ} \mathrm{C}$ 'de kürlenen karışımlar için genleşmeă̆ırlık artışı ilişkisi

Tablo 8'de görülen sonuçlara göre, $\mathrm{Na}_{2} \mathrm{O}$ eşdeğeri cinsinden ifade edildiğinde karışımda başlangıçta daha yüksek miktarda alkali bulunması genel bir kural olarak daha yüksek miktarda sızıntıya da neden olmuştur. Cam içeren karışımlarda alkali sızıntısı yüzdelerinin kontrol karışımlarına kıyasla önemli ölçüde daha yüksek olması cam agregalarından olası alkali salınımını akla getirmektedir. Artan sıcaklık seviyesi difüzyonu hızlandırdığından $[1,12] 60^{\circ} \mathrm{C}$ 'de yüzde cinsinden kaydedilen değerler de $38^{\circ} \mathrm{C}^{\prime}$ ye kryasla $1,5-5,2$ kat aralığında daha yüksek çıkmıştır.

0,063/3LA, 0,063/3HA ve 0,063/3MA karışımlarında $63 \mu$ m'dan küçük tanelerin uzaklaştırılması, cam içeren diğer karışımlara kıyasla yüksek geçirimlilikleri nedeniyle daha yüksek alkali sızıntısı seviyelerinin oluşmasına yol açmıştır. Örnek olarak, Tablo 5 'te verilen karışım oranlarından da görülebileceği üzere, 0/3HA ve 0,063/3HA karışımlarında dizaynda eşit miktarlarda cam agregası kullanılmıştır. Camda yer alan çok ince tanelerin alkali-silis reaksiyonuna sebep olmadığı bilindiğinden 0,063/3HA karışımının daha fazla reaktif bileşene sahip olduğu açıktır. $63 \mu \mathrm{m}$ 'dan küçük taneler içermeyen karışımlar, yüksek geçirimliliklerine ve reaksiyona yatkın olan daha fazla bileşen içermelerine rağmen genel olarak, daha yüksek genleşme seviyeleri göstermemişlerdir (Şekil 4 ve 5). O halde bu 
karışımlarda gerçekleşen yüksek alkali sızıntısı seviyelerinin genleşmeler üzerinde oldukça etkin rol oynadığı anlaşılmaktadır. Alkali sızıntısı sonuçları arasında ölçülen en yüksek değere $0,063 / 3 \mathrm{HA}$ karıșımının $60^{\circ} \mathrm{C}$ 'de bekletilmesi sonucunda rastlanmıștır. Bu karıșımda belirlenen $\% 44,92^{\prime}$ lik alkali kaybı, başlangıçta $4,60 \mathrm{~kg} / \mathrm{m}^{3}$ olan alkali içeriğinin $60^{\circ} \mathrm{C}$ 'de bekletilme neticesinde teorik olarak $2,53 \mathrm{~kg} / \mathrm{m}^{3}$ seviyesine düşmesi anlamına gelmektedir.

Tablo 8. Kontrol karışımları ile cam agregalı karışımlarda deney süreleri sonunda sızan alkali miktarları

\begin{tabular}{|c|c|c|c|c|c|}
\hline & $\begin{array}{l}\text { Bir prizmada } \\
\text { deneyler } \\
\text { öncesindeki } \\
\text { alkali miktarı } \\
\left(\mathrm{g}-\mathrm{Na}_{2} \mathrm{O}\right. \\
\text { eşd })\end{array}$ & $\begin{array}{l}38^{\circ} \mathrm{C} \text { 'ye maruz } \\
\text { kalma sonucunda } \\
52 \text { hafta sonundaki } \\
\text { alkali sızıntısı (mg } \\
\quad-\mathrm{Na}_{2} \mathrm{O} \text { eşd) }\end{array}$ & $\begin{array}{c}38^{\circ} \mathrm{C} \text { 'ye maruz } \\
\text { kalma sonucunda } \\
52 \text { hafta } \\
\text { sonundaki alkali } \\
\text { kayb1 (\%) }\end{array}$ & $\begin{array}{c}60^{\circ} \mathrm{C} \text { 'ye maruz } \\
\text { kalma sonucunda } \\
20 \text { hafta sonundaki } \\
\text { alkali sızıntısı (mg } \\
-\mathrm{Na}_{2} \mathrm{O} \text { eşd) }\end{array}$ & $\begin{array}{c}60^{\circ} \mathrm{C}^{\prime} \text { ye maruz } \\
\text { kalma sonucunda } \\
20 \text { hafta } \\
\text { sonundaki alkali } \\
\text { kayb1 }(\%)\end{array}$ \\
\hline Kontrol- & 7,04 & 421,38 & 5,99 & 1054,66 & 14,98 \\
\hline Kontrol & 8,80 & 793,78 & 9,02 & 1640,33 & 18,64 \\
\hline Kontrol+ & 10,56 & 1263,86 & 11,97 & 1868,89 & 17,70 \\
\hline $0 / 3 \mathrm{LA}$ & 4,46 & 195,20 & 4,38 & 1020,91 & 22,89 \\
\hline 0/3HA & 7,36 & 758,68 & 10,31 & 2561,06 & 34,80 \\
\hline 0/3MA & 5,90 & 702,71 & 11,91 & 2181,46 & 36,97 \\
\hline $0,063 / 3 \mathrm{LA}$ & 4,46 & 598,27 & 13,41 & 1663,31 & 37,29 \\
\hline $0,063 / 3 \mathrm{HA}$ & 7,36 & 2035,57 & 27,66 & 3306,46 & 44,92 \\
\hline $0,063 / 3 \mathrm{MA}$ & 5,90 & 1067,18 & 18,09 & 2348,37 & 39,80 \\
\hline
\end{tabular}

\section{SONUÇLAR}

$\mathrm{Bu}$ çalışmada özellikleri açıklanan malzemeler kullanılarak üretilen karışımlar üzerinde uygulanan beton prizma deneyleri, şu bulguları ortaya çıkartmıştır:

- Bazalt agregasının hızlandırılmış harç çubuğu deneyinde yüksek, beton prizma deneylerinde ise nispeten düşük reaktiviteye yol açtı̆̆ı, bir başka ifadeyle deney tekniği baz alındığında genleşme davranışları arasında uyumsuzluk görüldüğü belirlenmiş̧ir.

- Karışımlarda atık cam agregası kullanılması, reaksiyon hızında ve nihai genleşme seviyelerinde önemli ölçüde artışa yol açmıştır. Deney süreleri sonlansa da cam agregalı karışımların çoğu genleşme göstermeye halen devam etmektedir.

- Spektrometre verilerine göre $63 \mu$ m'dan küçük cam tanelerinin uzaklaştırıldığı karışımlarda daha fazla miktarda alkali sızıntısı gerçekleşmiş ve bu durum genleşmeleri düşürmüştür. Karışımların başlangıçtaki alkalinite seviyesi ve sıcaklık da alkali sızıntısı değerleri üzerinde önemli rol oynamıştır.

- AAR-3 ve AAR-4 deneyleri sonunda ölçülen alkali sızıntısı seviyeleri sırasıyla \%4,3827,66 ve \%14,98-44,92 aralıklarında değişkenlik göstermiştir. 
Bazalt ve Atık Cam Agregalı Betonlarda Alkali-Silis Reaksiyonu Genleşmeleri ve ...

\section{Teşekkür}

Bu yayında sunulan sonuçların tamamı, TÜBİTAK 110M569 projesinden sağlanan destekle elde edilmiştir. Yazarlar, sağladığı burs desteği ve çimentoların kimyasal analizini gerçekleştirmesi nedeniyle TÇMB'ye, sağlanan mali destek için EBILTEM'e (2012-BIL023 kodlu projeyle) ve agregaların kimyasal analizini gerçekleştiren Çimentaş İzmir Çimento Fabrikası ve Şişe Cam bünyesindeki Bilecik Camiş Madencilik'e teşekkürü bir borç bilirler.

\section{Kaynaklar}

[1] Lindgård, J., Andiç-Çakır, Ö., Fernandes, I., Rønning, T.F. and Thomas, M.D.A. (2012). Alkali-silica reactions (ASR): Literature review on parameters influencing laboratory performance testing. Cement and Concrete Research. Vol. 42, pp. 223243.

[2] Bérubé, M.A., Dorion, J.F., Rivest, M. (2000). Distribution of alkalies in concrete structures affected by alkali-silica reactivity and contribution by aggregates. Proceedings 11th International Conference on AAR, June, pp. 139-148, Québec City, Canada.

[3] Castro, N. and Wigum, B.J. (2012). Assessment of the potential alkali-reactivity of aggregates for concrete by image analysis petrography. Cement and Concrete Research. Vol. 42, pp. 1635-1644.

[4] Stanton, T.E. (1940). Expansion of concrete through reaction between cement and aggregate. Proceedings of the American Society of Civil Engineers, 66, pp. 17811811.

[5] Alnaggar, M., Cusatis, G. and Di Luzio, G. (2013). Lattice discrete particle modeling (LDPM) of alkali silica reaction (ASR) deterioration of concrete structures. Cement and Concrete Composites. Vol. 41, pp. 45-59.

[6] Thomas, M., Fournier, B., Folliard, K., Ideker, J. and Shehata, M. (2006). Test methods for evaluating preventive measures for controlling expansion due to alkalisilica reaction in concrete. Cement and Concrete Research. Vol. 36, pp. 1842-1856.

[7] Oberholster, R.E. and Davies, G. (1986). An accelerated method for testing the potential alkali reactivity of siliceous aggregates. Cement and Concrete Research. Vol. 16, pp. 181-189.

[8] Fournier, B., Bérubé, M.A. and Frenette, J. (2000). Laboratory investigations for evaluating potential alkali-reactivity of aggregates and selecting preventive measures against alkali-aggregate reaction (AAR) - What do they really mean? Proceedings 11th International Conference on AAR, June, pp. 287-296, Québec City, Canada.

[9] De Grosbois, M. and Fontaine, E. (2000). Evaluation of the potential alkali-reactivity of concrete aggregates: Performance of testing methods and a producer's point of view. Proceedings 11th International Conference on AAR, June, pp. 267-276, Québec City, Canada. 
[10] Ideker, J.H., East, B.L., Folliard, K.J., Thomas, M.D.A. and Fournier, B. (2010). The current state of the accelerated concrete prism test. Proceedings of the 13th International Conference on AAR, June 16-20, pp. 119-129, Trondheim, Norway.

[11] Ranc, R. and Debray, L. (1992). Reference test methods and a performance criterion for concrete structures. Proceedings of the 9th International Conference on AAR in concrete, pp. 824-831, London, UK.

[12] Fournier, B., Chevrier, R., De Grosbois, M., Lisella, R., Folliard, K., Ideker, J., Shehata, M., Thomas, M. and Baxter, S. (2004). The accelerated concrete prism test $\left(60^{\circ} \mathrm{C}\right)$ : Variability of the test method and proposed expansion limits. Proceedings of the 12th International Conference on AAR in Concrete, pp. 314-323, Beijing, China.

[13] Shayan, A., Xu, A. and Morris, H. (2008). Comparative study of the concrete prism test $\left(\mathrm{CPT} 60^{\circ} \mathrm{C}, 100 \% \mathrm{RH}\right)$ and other accelerated tests. Proceedings of the 13th International Conference on AAR, June 16-20, pp. 391-400, Trondheim, Norway.

[14] Murdock, K.J. and Blanchette, A. (1994). Rapid evaluation of alkali aggregate reactivity using a $60^{\circ} \mathrm{C}$ concrete prism test, Proceedings of the $3 \mathrm{rd}$ CANMET/ACI International Conference on Durability of Concrete, pp. 57-78, Nice, France.

[15] Touma, W.E., Fowler, D.W., Carrasquillo, R.L., Folliard, K.J. and Nelson, N.R. (2001). Characterizing alkali-silica reactivity of aggregates using ASTM C1293, ASTM C1260 and their modifications. Transportation Research Record, 1757, Paper no. 01-3019, pp. 157-165.

[16] Lindgård, J., Nixon, P.J., Borchers, I., Schouenborg, B., Wigum, B.J., Haugen, M. and Åkesson, U. (2010). The EU "PARTNER" Project - European standard tests to prevent alkali reactions in aggregates: Final results and recommendations. Cement and Concrete Research. Vol. 40, pp. 611-635.

[17] Rivard, P., Bérubé, M.A., Ollivier, J.P. and Ballivy, G. (2003). Alkali mass balance during the accelerated concrete prism test for alkali-aggregate reactivity. Cement and Concrete Research. Vol. 33, pp. 1147-1153.

[18] Duchesne, J. and Bérubé, M.A. (2001). Long-term effectiveness of supplementary cementing materials against alkali-silica reaction. Cement and Concrete Research. Vol. 31, pp. 1057-1063.

[19] Lindgård, J., Thomas, M.D.A., Sellevold, E.J., Pedersen, B., Andiç-Çakır, Ö., Justnes, H. and Rønning, T.F. (2013a). Alkali-silica reaction (ASR) - performance testing: Influence of specimen pre-treatment, exposure conditions and prism size on alkali leaching and prism expansion. Cement and Concrete Research. Vol. 53, pp. 68-90.

[20] Çopuroğlu, O., Andiç-Çakir, Ö., Broekmans, M.A.T.M. and Kühnel, R. (2009). Mineralogy, geochemistry and expansion testing of an alkali-reactive basalt from western Anatolia, Turkey. Materials Characterization, Vol. 60, pp. 756-766.

[21] Yüksel, C., Saleh-Ahari, R., Abbaspoursani-Ahari, B. and Ramyar, K. (2013). Evaluation of three test methods for determining the alkali-silica reactivity of glass aggregate. Cement and Concrete Composites. Vol. 38, pp. 57-64. 
Bazalt ve Atık Cam Agregalı Betonlarda Alkali-Silis Reaksiyonu Genleşmeleri ve ...

[22] RILEM State-of-the-Art Reports, Volume 17 (2016). State-of-the-Art-Report of the RILEM Technical Committee 219-ACS, RILEM Recommendations for the Prevention of Damage by Alkali-Aggregate Reactions in New Concrete Structures. Eds. Philip J. Nixon and I. Sims.

[23] Lindgård, J., Sellevold, E.J., Thomas, M.D.A., Pedersen, B., Justnes, H. and Rønning, T.F. (2013b). Alkali-silica reaction (ASR) - performance testing: Influence of specimen pre-treatment, exposure conditions and prism size on concrete porosity, moisture state and transport properties. Cement and Concrete Research. Vol. 53, pp. 145-167.

[24] Robinson, J.W. (1982). Basic Principles. In: J.E. Cantle (ed) Atomic Absorption Spectrometry. Elsevier Scientific Publishing Company. New York, pp. 1-14.

[25] Shayan, A. (2004). Alkali-aggregate reaction and basalt aggregates. Proceedings of the 12th International Conference on AAR in Concrete, pp. 1130-1135, Beijing, China.

[26] Du, H. and Tan, K.H. (2013). Use of waste glass as sand in mortar: Part II - Alkalisilica reaction and mitigation methods. Cement and Concrete Composites, Vol. 35, pp. 118-126.

[27] Hudec, P.P. and Ghamari, R.C. (2000). Ground waste glass as an alkali-silica reactivity inhibitor. Proceedings 11th International Conference on AAR, June, pp. 663-672, Québec City, Canada.

[28] Shao, Y., Lefort, T., Moras, S. and Rodriguez, D. (2000). Studies on concrete containing ground waste glass. Cement and Concrete Research, Vol. 30, pp. 91-100.

[29] Rajabipour, F., Maraghechi, H. and Fischer, G. (2010). Investigating the alkali-silica reaction of recycled glass aggregates in concrete materials. Journal of Materials in Civil Engineering. 22, (12), pp. 1201-1208. 